\title{
A Survey on WSN and MCN Convergence Networks
}

\author{
Anita Swain and Arun Kumar Ray \\ School of Electronics Engineering, KIIT Deemed to be University, Bhubaneswar, India
}

https://doi.org/10.26636/jtit.2020.137619

\begin{abstract}
In this paper, we present a survey concerned with research focusing on the convergence of wireless sensor networks (WSN) and mobile cellular networks (MCN). The convergence of WSNs and MCNs may be a trigger stimulating new research dealing with such issues as architecture, protocols and air interfaces. The highlights and constraints of the phenomenon are discussed in this paper as well. The survey deals with convergence networks and with their smarty city applications. A few open research issues are also brought to the attention of researchers specializing in this field.
\end{abstract}

Keywords-IPv4, MAC layer, machine-to-machine network, QoS.

\section{Introduction}

A wireless sensor network (WSN) is a network of ad-hoc nodes (sensor nodes) deployed in a physical environment to collect information for different applications. It is used for sensing, processing and communicating information regarding temperature, pressure, vibrations, humidity [1], [2]. Considerable research has already been carried out over the past two decades on different design aspects of WSNs in order to address the challenges affecting different applications [3]. The design aspects focus on software and hardware constraints, power consumption (battery life), architecture design and topology management, protocol stack and cross layer issues, time synchronization and location techniques, and on communication standards [2]. Many research articles address issues related to the MAC layer and network layer [4], [5]. WSN designs also take into consideration such factors as fault tolerance, power consumption, scalability, latency, data integrity, security, low cost and quality of service (QoS).

WSN sensors are deployed at remote locations to collect and process information for different applications [6]. In some cases, the information may also be routed through a mobile cellular network (MCN) [7]. Therefore, the flow of information between WSNs and MCNs should be seamless. For example, in health monitoring applications, information about the patient's vital body parameters needs to be sent to a physician using a body area network [8]. Light wireless wearable medical devices with specialized sensors are used to collect medical data. The information can be routed through mobile phones that act as gateways to the hospital's server unit. Many such applications can be developed for smart cities using both WSNs and MCNs. The convergence of WSNs and MCNs may be potentially beneficial for both solutions. In this paper, we made an attempt to review literature on the convergence of WSNs and MCNs and on the research challenges lying ahead.

In general, convergence of two heterogeneous networks, such as WSNs and MCNs, may enhance machine-to-machine (M2M) communication [9]. For example, the Internet of Things (IoT) - a concept that originates from a WSN, plays an important role in creating the infrastructure of a communications network [10]. Lower mobility-related robustness, small coverage and weak terminals of WSNs may be overcome by the mobility, robustness, large coverage and powerful terminals of MCNs [11]. The processes of deploying and managing MCNs are expensive compared to WSNs. However, MCNs offer a higher degree of layer control, prolonged network life time and provide QoS for WSNs. Similarly, WSNs may also act as enablers of the cognitive and intelligent aspects of MCNs. Therefore, further research focusing on the development of data-centric applications and services for convergent networks needs to be conducted. Furthermore, new enabling technologies should be developed for WSN and MCN convergence networks in order to support emerging applications.

In this paper, we discuss a protocol enabling the convergence of WSNs and MCNs. The paper aims to discuss the evolution of WSN-MCN convergence networks, as well as the architectural and protocol-related aspects of their convergence, with a particular emphasis on the resources involved. It also aims to describe a specific convergence between a 6LoWPAN stack and an LTE stack - relying on the support derived from literature. We provide certain hints concerning the use of WSNs in $5 \mathrm{G}$ environments. We also raise some important research issues that need to be dealt with as future work.

\section{Related Work}

The integration of ad-hoc sensor networks (ASN) with cellular networks, for telemedicine-related applications, is explained in [12]. The author proposes a call admission control (CAC) method and a sensor network query algorithm to meet the QoS requirements. Paper [13] proposes the IoMANETS mobility framework to enable fault-tolerant 
and scalable solutions for the mobile Internet of Things. Whereas static nodes connect to the Internet through IPv4 or IPv6 protocols, mobile nodes function in an IEEE 802.15.4 working group operating on the 6LoWPAN IP stack. In [14], the authors present the idea of a WSN and MCN convergence network based on a heterogeneous network. In this paper, the authors describe the architecture of the system and specify applications for convergence networks. They also identify the technical challenges that need to be solved in order for WSNs and MCNs to become a convergence network.

Authors of [11] propose that mobile terminals in MCNs act as WSN sensor nodes and gateways in the converged network. The authors also differentiate by describing two separate architectures for integrated and convergence networks, by using a dual mode gateway. Although the description of the convergence protocol is provided, no specific MCN and WSN convergence network is mentioned.

In paper [15], a solution comprising a long term evolution advance (LTE-A) cellular network and a 6LoWPAN WSN is proposed to solve the quality-of-service issue through network delay in tight and loose coupling of the LTE-A configuration. The results presented show that network delay of their proposed method is acceptable for various M2M networks.
In [16], the authors proposed a node and network model for achieving Internet protocol (IP)-based direct communication in an M2M network or IoT. The authors' proposal may be a solution to the end-to-end connection between the WSN and MCN convergence network. Paper [17] proposes an algorithm balancing the load between UE gateways in a WSN and MCN convergent system. The authors describe the balancing of sensor load between mobile gateways as a new research point concerning convergence networks. In [18], an energy-efficient data collection method is proposed to reduce and balance energy expenditure between the sensors in a WSN and MCN convergence network. The purpose of the concept is to activate some sensors for data collection while allowing other sensors to sleep.

\section{Converging Technology}

The goal of this paper is to review the convergence between WSNs and MCNs. We are focusing on some of the challenges faced during the process. Protocol conversion is playing one of the leading roles here. Table 1 shows various WSN protocols and their related issues. To perform a protocol conversion, the protocol stacks of two heterogeneous networks need to be deployed. However, it requires

Table 1

WSN protocols and research issues

\begin{tabular}{|c|c|c|c|}
\hline WSN layers & Protocols & Functions & Research issues \\
\hline $\begin{array}{l}\text { Data link } \\
\text { layer }\end{array}$ & $\begin{array}{l}\text { - TRAMA [19] } \\
\text { - B-MAC [20] } \\
\text { - ZMAC [21] } \\
\text { - Low power reservation } \\
\text { based MAC [22] } \\
\text { - Low power distributed } \\
\text { MAC [23] } \\
\text { - CC-MAC [24] }\end{array}$ & $\begin{array}{l}\text { The concept of a link layer for trans- } \\
\text { ferring data between two nodes which } \\
\text { needs is created, needing a medium ac- } \\
\text { cess control (MAC) to share the same } \\
\text { link. Such properties as energy effi- } \\
\text { ciency, bandwidth utilization, traffic flow } \\
\text { control and error detection and correc- } \\
\text { tion should be focused on to ensure effi- } \\
\text { cient data communication }\end{array}$ & $\begin{array}{l}\text { More cross-layer optimization- } \\
\text { related research is required to } \\
\text { reduce energy consumption and } \\
\text { packet overheads. The empha- } \\
\text { sis should be placed on mobile } \\
\text { rather than on static nodes }\end{array}$ \\
\hline $\begin{array}{l}\text { Network } \\
\text { layer }\end{array}$ & $\begin{array}{l}\text { - } \text { Geographical } \\
\text { routing [25] } \\
\text { - ALS [26] } \\
\text { - SecRout [27] } \\
\text { - SCR [28] } \\
\text { - APTEEN [29] } \\
\text { - Energy aware QoS } \\
\text { routing protocol [30] } \\
\text { - MMSPEED [31] } \\
\text { - Sleep scheduling } \\
\text { routing protocol [32] }\end{array}$ & $\begin{array}{l}\text { Routing of data within the network, from } \\
\text { source to destination, by considering } \\
\text { such factors as energy efficiency, traffic } \\
\text { flow control and QoS }\end{array}$ & $\begin{array}{l}\text { Issues related to QoS, se- } \\
\text { curity and node mobility } \\
\text { should be further researched to } \\
\text { improve data routing }\end{array}$ \\
\hline $\begin{array}{l}\text { Transport } \\
\text { layer }\end{array}$ & $\begin{array}{l}\text { - STCP [33] } \\
\text { - PORT [34] } \\
\text { - DST [35] } \\
\text { - PSFQ [36] } \\
\text { - ESRT [37] } \\
\text { - CODA [38] } \\
\text { - GARUDA [39] }\end{array}$ & $\begin{array}{l}\text { To achieve the congestion-free and } \\
\text { reliable data transportation }\end{array}$ & $\begin{array}{l}\text { Cross layer optimization to im- } \\
\text { prove performance, ensure fair- } \\
\text { ness in terms of packet priority } \\
\text { and provide congestion control } \\
\text { with active queue management }\end{array}$ \\
\hline
\end{tabular}


Table 2

Wireless communication standards

\begin{tabular}{|l|c|c|c|c|c|}
\hline \multicolumn{1}{|c|}{$\begin{array}{c}\text { Communication } \\
\text { standard }\end{array}$} & Frequency & $\begin{array}{c}\text { Operating } \\
\text { range }\end{array}$ & $\begin{array}{c}\text { Data } \\
\text { rate }\end{array}$ & $\begin{array}{c}\text { Battery } \\
\text { life }\end{array}$ & $\begin{array}{c}\text { Network } \\
\text { topology }\end{array}$ \\
\hline $\begin{array}{l}\text { ZigBee } \\
\text { (IEEE 802.15.4) }\end{array}$ & $\begin{array}{l}868 \mathrm{MHz} \\
915 \mathrm{MHz} \\
2.4 \mathrm{GHz}\end{array}$ & $10-100 \mathrm{~m}$ & $\begin{array}{c}20 \mathrm{Kbps} \\
40 \mathrm{Kbps} \\
250 \mathrm{Kbps}\end{array}$ & $>1$ year & Mesh, ad hoc and star \\
\hline $\begin{array}{l}\text { Bluetooth } \\
\text { (IEEE 802.15.1) }\end{array}$ & $2.4 \mathrm{GHz}$ & $10 \mathrm{~m}$ & $1-3 \mathrm{Mbps}$ & 1 week & $\begin{array}{c}\text { Ad hoc, point to point } \\
\text { and star }\end{array}$ \\
\hline UWB (IEEE 802.15.3) & $3.1-10.6 \mathrm{GHz}$ & $<10 \mathrm{~m}$ & $100-1024 \mathrm{Mbps}$ & 1 week & Ad hoc, point to point \\
\hline Wi-Fi (IEEE 802.11a/b/g) & $\begin{array}{c}11 \mathrm{~b} / \mathrm{g}-2.4 \mathrm{GHz} \\
11 \mathrm{a}-5 \mathrm{GHz}\end{array}$ & $<100 \mathrm{~m}$ & $\begin{array}{c}11 \mathrm{a}<54 \mathrm{Mb} / \mathrm{s} \\
11 \mathrm{~b}<11 \mathrm{Mb} / \mathrm{s} \\
11 \mathrm{~g}>54 \mathrm{Mb} / \mathrm{s}\end{array}$ & Hours & Star \\
\hline Wibree & $2.4 \mathrm{GHz}$ & $5-10 \mathrm{~m}$ & $1 \mathrm{Mbps}$ & $1-2$ years & Mesh, ad hoc and star \\
\hline MiWi protocol & $2.4 \mathrm{GHz}$ & $20-50 \mathrm{~m}$ & $256 \mathrm{Kbps}$ & & Star, cluster and mesh \\
\hline 6LoWPAN & $2.4 \mathrm{GHz}$ & $116 \mathrm{~m}$ & $250 \mathrm{Kbps}$ & $1-2$ years & Star and mesh \\
\hline
\end{tabular}

Table 3

Comparison of mobile cellular technologies

\begin{tabular}{|c|c|c|c|c|c|c|c|c|}
\hline $\begin{array}{c}\text { Genera- } \\
\text { tions }\end{array}$ & $\begin{array}{c}\text { Deployment } \\
\text { (year) }\end{array}$ & $\begin{array}{c}\text { Tech- } \\
\text { nology }\end{array}$ & Standard & $\begin{array}{c}\text { Data } \\
\text { rate }\end{array}$ & Bandwidth & Frequency & Characteristics & Switching \\
\hline $1 \mathrm{G}$ & 1979 & FDMA & NMT & $2 \mathrm{Kbps}$ & $150 / 900 \mathrm{MHz}$ & $\begin{array}{c}\text { Analog } \\
\text { signal } \\
30 \mathrm{kHz}\end{array}$ & $\begin{array}{c}\text { First wireless } \\
\text { communi- } \\
\text { cation }\end{array}$ & Circuit \\
\hline $2 \mathrm{G}$ & 1991 & $\begin{array}{c}\text { TDMA, } \\
\text { FDMA }\end{array}$ & $\mathrm{GSM}$ & $9.6 \mathrm{Kbps}$ & $900 \mathrm{MHz}$ & $\begin{array}{c}\text { Digital } \\
\text { signal } \\
1.8 \mathrm{GHz}\end{array}$ & Digital & $\begin{array}{c}\text { Circuit, } \\
\text { packet }\end{array}$ \\
\hline $3 \mathrm{G}$ & 2000 & $\begin{array}{c}\text { TDMA, } \\
\text { CDMA }\end{array}$ & UMTS & $2 \mathrm{Mbps}$ & $100 \mathrm{MHz}$ & $1.6-2.0 \mathrm{GHz}$ & $\begin{array}{c}\text { Digital broad } \\
\text { band, increased } \\
\text { speed }\end{array}$ & Packet \\
\hline $4 \mathrm{G}$ & 2009 & OFDMA & LTE & $1 \mathrm{Gbps}$ & $100 \mathrm{MHz}$ & $2-8 \mathrm{GHz}$ & $\begin{array}{c}\text { High speed, } \\
\text { all IP based }\end{array}$ & Packet \\
\hline $5 \mathrm{G}$ & 2020 & OFDMA & $5 \mathrm{G} \mathrm{NR}$ & $1 \mathrm{Gbps}$ & $\begin{array}{c}1000 \times \mathrm{BW} \\
\text { per unit area }\end{array}$ & $3-300 \mathrm{GHz}$ & $\begin{array}{c}\text { Up to } 100 \times \\
\text { number of con- } \\
\text { nected devices } \\
\text { per unit area }\end{array}$ & Packet \\
\hline
\end{tabular}

a converging technology. Based on the converging communication standards presented in Table 2, we have described the 6LoWPAN standard and have specified its protocol conversion technique when applied in an LTE-A network.

As shown in Table 2, such parameters as operating frequency, range, data rate, battery life and network topology are significant aspects of the communication process. These parameters help in the successful deployment of WSNs in different applications. Various research articles have reported ZigBee to be the most preferred and appropriate standard for WSNs [40]. It has more adaptable features than Bluetooth, such as long battery life, secure and simple communication. The IEEE 802.15.4 document defines the security and network protocol for the ZigBee technology [41]. In [42], the authors study industrial ap- plications of ZigBee and Bluetooth. ZigBee is capable of meeting a wider variety of real industrial needs than Bluetooth due to its long-term battery operation, greater useful range, flexibility in a number of dimensions and reliability of the mesh networking architecture. However, it seems that UWB is the best emerging technology for ubiquitous computing in short range applications, due to its better interference handling capabilities [43]. As far as the data rate is concerned, Wi-Fi is considered to be one of the best alternatives, and the addition of a mobile device makes it more appropriate for advanced applications [44]. Such standards as Wibree, NFC and MiWi are mostly useful for mobile users [45], [46].

However, if we consider the convergence of a WSN with a cellular network, then 6LoWPAN may turn out to be one 
of the suitable protocols to converge with an LTE-A network [15], [47], [48]. The IEEE 802.15.4 standard was introduced to define low-rate wireless personal area networks. It defines the physical and media access control layer for LoWPAN networks [49]. The IEEE 802.15.4 protocol distinguishes three operational modes: $20 \mathrm{Kbps}$ at $868 \mathrm{MHz}, 40 \mathrm{Kbps}$ at $915 \mathrm{MHz}$, and $250 \mathrm{Kbps}$ at $2.4 \mathrm{GHz}$. The network layer protocols should be compatible with the limitation inherent in lower layer protocols.

Requirements applicable to the IPv6 protocol differ from the IEEE 802.15.4-imposed limitations. For example, the minimum IPv6 MTU is 1500 bytes, whereas IEEE 802.15.4 requires 127 bytes [50]. Along with this incompatibility, the IPv6 header results in a compact payload for higher protocols. To overcome these problems, an IETF 6LoWPAN working group has been established to support the use of IPv6 over IEEE 802.15.4 [51]. The 6LoWPAN working group addresses the following issues [52]: less extension of IPv6 neighbor discovery protocol for supporting WSN, compression of 6LoWPAN headers, and description of 6LoWPAN routing protocols supporting WSN characteristics. In order to support IPv6 over IEEE 802.15.4, an extra adaptation layer has been established between the data link layer and the network layer. 6LoWPAN uses stacked headers, just like IPv6, rather than single headers used in IPv4. A comparison of different MCN technologies used in different generations of cellular networks is presented in Table 3.

\section{WSN Towards Convergence}

Various studies indicate that WSNs are prone to lower degree of mobility robustness, small coverage and weak terminals [11], [13]. In addition, WSNs are flexible enough to support various smart applications. On the other hand, MCNs offer features making it possible to combine them with WSNs. As discussed in Section 2, their convergence will lead to the development of applications capable of solving real life problems. It is reported in literature and speculated by the scientific community that the convergence of WSNs and MCNs may benefit each of those solutions [11]. The following benefits may encourage the research community to focus on convergence and on related applications:

- MCNs may enable a higher degree of layer control and optimization to increase network life, WSN performance and to provide better QoS with the use of WSNs,

- WSNs may serve as enablers of cognitive and intelligent aspects of cellular systems,

- the architecture of a WSN and MCN convergence network enables wireless services and more data centric applications,

- MCNs may make WSNs more efficient in terms of energy consumption and better network performance,
- convergence networks may be used in telemetry and remote management applications due to supervisory control and data acquisition systems they rely on,

- mobile MCN terminals may act both as sensor nodes and gateways for WSNs.

The authors have found out that the number of research articles published that focus on convergence is rather low during the initial stage of the development process. Therefore, the current review will definitely help researchers in the future. In WSN and MCN convergence networks, sensor nodes collect information and send it to the data server through MCN [53]. Therefore, a set of issues arises when the two heterogeneous networks referred to above converge. The following issues need to be addressed in relation to the convergence of WSN and MCN networks.

\subsection{Network Architecture}

The WSN-MCN network architecture may be classified as an integrated network and a convergence network. The integrated network is based on the layered approach, where wireless sensor nodes belonging to WSN form the bottom layer of the network and are used to sense and collect data. The upper layer consists of the base station. The middle layer is the gateway that communicates with controls the WSN nodes. The gateways used in this architecture have the form of mobile terminals or mobile MCN stations acting as dual mode gateways [54]. Here, the gateway is responsible for controlling WSN indirectly, through the base station. The dual mode gateway may provide access to WSN nodes and may forward information to the network server. The dual mode gateway is based on 6LoWPAN technology accepting data from WSN in one mode, and being available for MCN data transmission in the other mode. Moreover, the dual mode gateways switch from one network mode to another, i.e. from WSN to MCN, by changing their packet format from the WSN standard to the MCN standard, and vice versa. This is a specific type of WSN and MCN integration, where the gateway is located in the middle layer to manage WSN nodes [11]. This integrated network architecture is shown in Fig. 1. However, usage of the data channel for communication between WSN and MCN decreases the system's efficiency.

In the convergence network, network architecture changes from the layered to flat [55]. This reduces the exchange of signals between both networks. Here, sensor nodes have the ability to listen directly to the MCN base station for downlink signaling, as the MCN offers large coverage. Therefore, MCN may directly control WSN nodes and may manage them in an efficient manner. The BS can help the WSN nodes in choosing the optimal path for data transmission. This type of architecture is shown in Fig. 2. However, WSN nodes offer limited data transmission range, so uplink traffic needs to be routed through the mobile MCN terminal which acts as a simple gateway for WSN traffic. In 


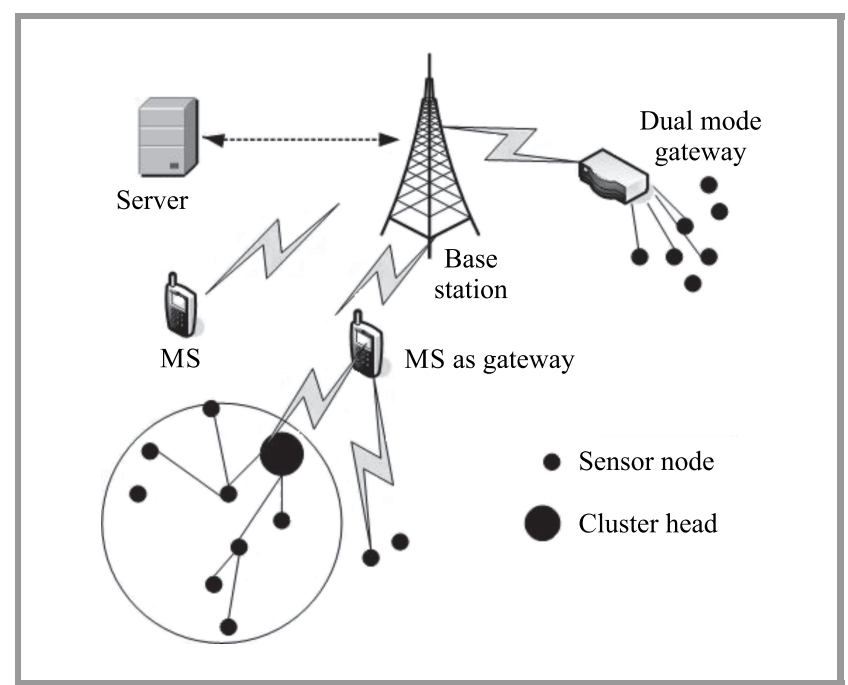

Fig. 1. Architecture of a WSN and MCN integrated network.

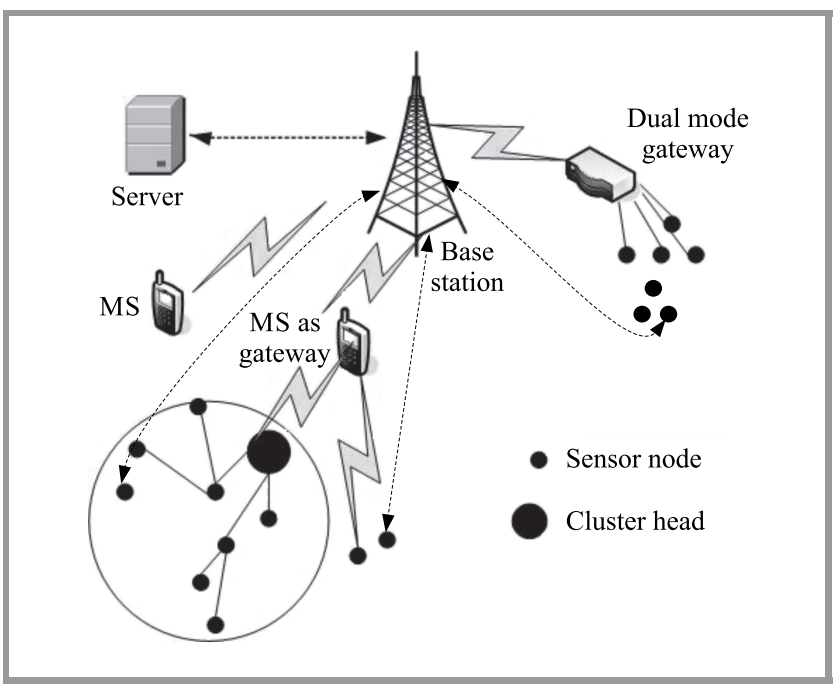

Fig. 2. Architecture of a WSN and MCN integrated network.

this scenario, the packet retains its original format, as used in the MCN protocol. This is the improvement distinguishing a convergence network from an integrated network.

Architecture-related issues are addressed with the help of highlights and constraints presented below. These highlights and constraints will determine new research directions for researchers focusing on convergence networks:

- as the base station exercises full control over the sensor nodes to store data and enable them to choose their optimal gateway and transmission path, additional signaling will be a challenge for convergence networks,

- a jointly optimized coordination scheme should be designed to allow the sensor nodes to achieve tradeoff between energy consumption and system performance.

\subsection{Air-Interface Convergence}

In a convergence network, two heterogeneous networks are converged, irrespective of their different air interfaces. Therefore, it is a challenge to design a converged air interface. Recent research shows that in terms of WSN air interfaces (e.g. Bluetooth and ZigBee), the narrow band technology or spread spectrum transceivers may be appropriate [11]. However, MCN uses different technologies, such as UMTS, LTE, WiMAX, etc. It is very simple to implement dual mode mobile terminals as shown in Fig. 2. One of the important limitations of this solution is that the mobile device will have to frequently switch the mode to send the data from WSN to the base station. Therefore, a suitable air interface technology is needed to avoid the complexity of the dual mode switching functionality of the gateway. Literature review highlighted orthogonal frequency division multiplexing (OFDM) as the forthcoming air interface technology for convergence networks [56], [57]. OFDM/OFDMA is suitable for sharing the radio resources between systems with different bandwidths. However, OFDM-based spectrum pooling (noncontinuous OFDM) has been given much attention recently in connection with air interface technology [58]. To meet the demands of higher data rates in the future, an OFDMbased air interface may be an alternative solution for WSNs. The highlights and constraints experienced here are as follows:

- one of the limitations of using a dual mode mobile phone is that it has to frequently switch or change the mode for receiving and sending data from WSN to MCN, which means that its complexity increases,

- the coverage and channel allocation schemes for WSNs and MCNs are different, as are the bandwidth and signal processing capabilities for which a cyclic prefix should be optimized jointly,

- both networks should work using the same frequency in order to reduce complexity and to increase network performance.

\section{Protocol Convergence}

The protocol stack for a WSN and MCN convergence network given in Fig. 3 comprises two independent stacks.

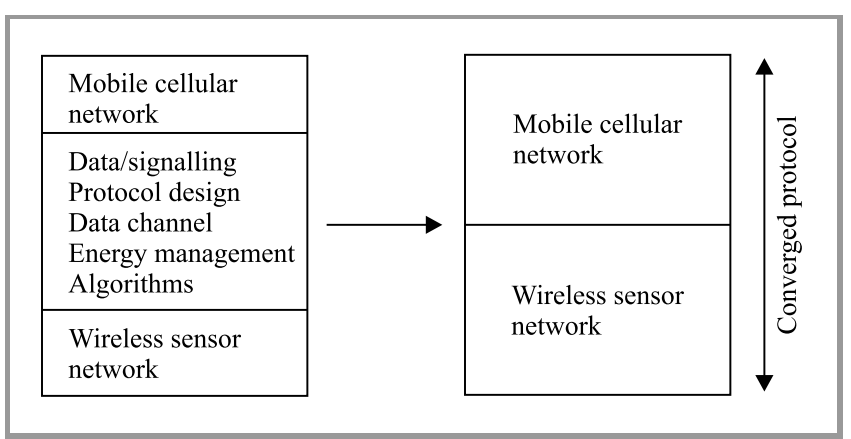

Fig. 3. Protocol stack for WSN and MCN convergence network. 
However, the two independent protocol stacks need further work in order to morph into a single converged protocol stack. Usually, the gateway (mobile device) is responsible for exchanging information between WSN and MCN. Therefore, data channels between two independent stacks at the gateway level need to be implemented. For an uninterrupted data exchange, uplink and downlink control signaling should be properly designed in order to support the convergence network. Along with improved algorithms, some cross-MAC needs to be implemented at the gateway level. At this point, new control signaling may impact the current WSN and MCN standards. Hence, this issue could be managed by the base station, by controlling the uplink and downlink signaling exchange. As reported by Zhang et al., the MAC layer and the network layer in the protocol stack of both networks should be jointly optimized to achieve performance gains for WSNs [11].

In the MAC layer, the resource allocation scheme should be considered for heavy traffic, i.e. for a large number of sensor nodes in WSN. Resource requests from WSN are routed to MCN through the gateway. The MCN base station allocates WSN channels groups (wireless sensor nodes) to each gateway. In the network layer, reselection of the gateway and re-clustering of the wireless sensor nodes encourage the development of a new converged routing protocol. The modulation scheme, as well as efficient control and encryption techniques need to be implemented between the two protocol stacks for physical layer optimization. The transport layer protocol should be modified to offer better convergence network congestion control in heavy traffic scenarios.

The aim of the $4 \mathrm{G}$ system is to establish a convergence relationship between all IP-based networks. In order to satisfy this goal, there is a need for integration of network management, security and QoS. An LTE-A networks satisfy the requirements applicable to convergence network platforms [59]. It is backward compatible with previous versions of 3 GPP standards, non-3GPP networks and most of IP-based networks, such as the Internet [60]-[62]. Other 4G technologies, such as $802.16 \mathrm{~m}$, may serve as a substitute for convergence networks, but most of the subscribers use LTE for wireless communication. Cost-effective deployment is another advantage of LTE [63], [64]. Here, we consider a specific protocol conversion between WSN and LTE-A networks. The protocol stack between 6LoWPAN and user equipment (UE), being the last node of the access layer of E-UTRAN, is not the same as in Fig. 4. Therefore, there is a need for protocol conversion in the gateway to ensure compatibility between packets received from WSN with the use of LTE-A, and vice versa.

In [65], [16], the authors explained protocol conversion in their proposed dual mode gateway. The first case considers data packets traveling from WSN to LTE-A, as shown in Fig. 5. As the connection is based on IP, there is no need to access the above layer of the IP layer. There is a need for IP tunnel encapsulation in order to convert IPv6 to IPv4

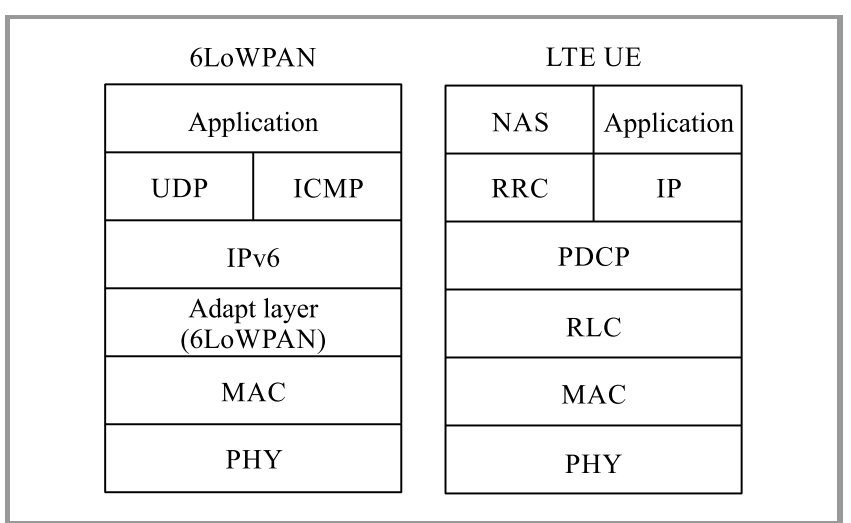

Fig. 4. Protocol stack of 6LoWPAN and LTE UE.

at the gateway level. This process should be performed to ensure end-to-end connectivity, due to compatibility of IPv4 with various networks. The MAC layer of LTE UE consists of the MAC header and RLC payload. The MAC header is 42 bytes long, whereas the payload is 400 bytes long. The maximum size of a packet arriving from WSN is 127 bytes, with additional 20 bytes for the IPv4 header that is added during the IP tunneling process [65]. This process increases the total maximum size to 147 bytes. Therefore, the packet coming from WSN fits in the LTE MAC layer payload. The compatibility of LTE networks promotes the transferring of data packets from WSNs to IP-based networks [66].

The second case involves the transferring of data packets from an LTE-A cellular network to WSN. The data packet consists of three headers, such as LTE, IPv4 and IPv6. WSN recognizes only the IPv6 header. Therefore, the packet containing the LTE and IPv6 headers can be discarded by WSN. The size of the LTE header is 42 bytes and that of the IPv4 header is 20 bytes. The dual mode gateway can easily recognize these headers. The dual mode gateway removes 62 bytes from the LTE-A packet.

\subsection{G Frame Structure and MAC Layer}

In $4 \mathrm{G}$, the frame length is $10 \mathrm{~ms}$ and each frame is divided into $10 \mathrm{sub}$-frames of $1 \mathrm{~ms}$. Three types of sub-frames exist, i.e. DL, UL and a special sub-frame, as shown in Fig. 6. UL and DL sub-frames are further divided into $0.5 \mathrm{~ms}$ slots. The special frame contains downlink pilot timeslot (DwPTS), guard period (GP) and uplink pilot timeslot (UpPTS) fields maintained by the 4G network's TDD.

Sub-frame-0, sub-frame-5 and DwPTS are reserved for downlink transmissions, while UpPTS and the sub-frame following the special sub-frame are reserved for uplink transmissions. Spreading of DL preamble OFDM symbol in the downlink sub-frame is used. It can be explained as PHY layer actions, such as initial channel estimation, noise and interference estimation, time and frequency synchronization. Such characteristics of the bursts as length and number are indicated by the DL frame control header. The broadcasting of channel allocation information is in- 

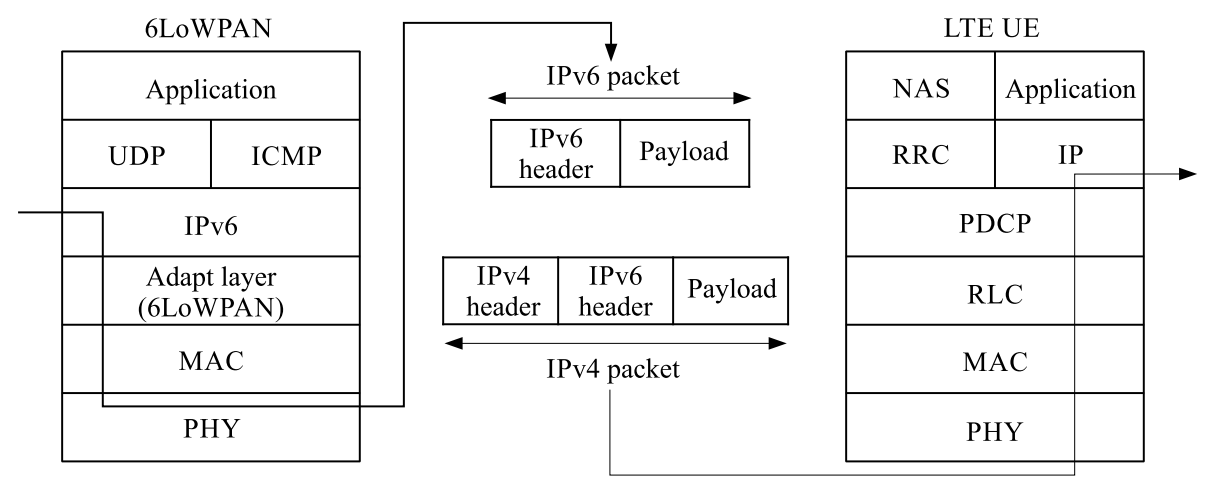

Fig. 5. Protocol conversion for transferring packets from a WSN to an LTE-A network.

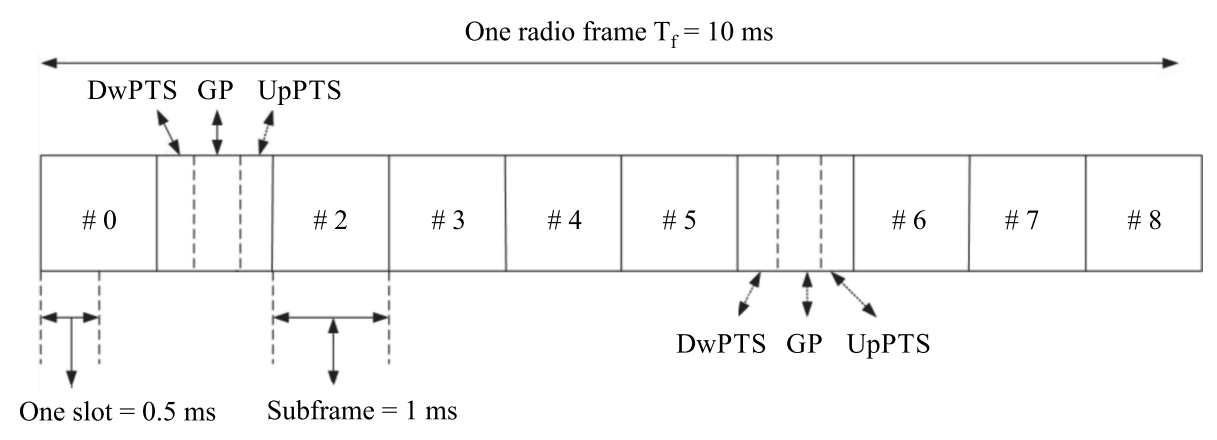

Fig. 6. MAC Frame structure in $4 \mathrm{G}$.

troduced by UL MAP and DL MAP. By listening to MAP messages, every user may recognize the data region assigned there to, both in DL and UL. A burst profile is allocated to the data burst and contains data for the specific user.

In 4G, the MAC layer provides service to the RLC layer by logical channel, error correction through HARQ, MAC Control contains the element control information and MAC payload. Data from the RLC layer is received by the MAC

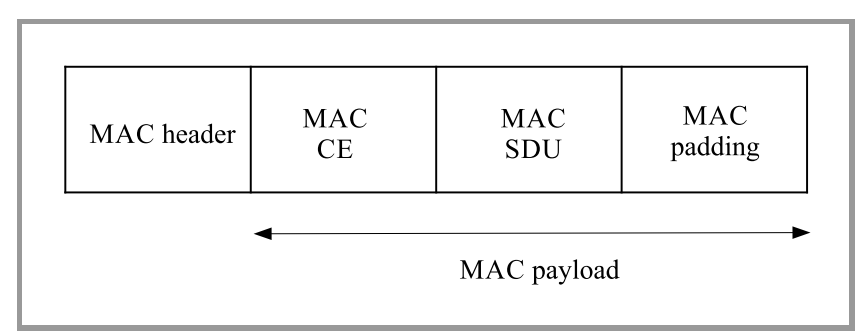

Fig. 7. MAC PDU structure in $4 \mathrm{G}$.

layer in the form of MAC SDU. A description regarding the size of the MAC PDU structure for $4 \mathrm{G}$ is shown in the MAC Overhead portion. The hybrid automatic repeat request (HARQ) is handled by the MAC layer. The MAC PDU structure is shown in Fig. 7.

\section{WSN and 5G MCN Convergence Scenario}

Rapid development of smart technology creates an environment fostering the deployment of sensor nodes used ever more commonly in our daily lives. The emerging 5G MCN is going to play a key role in converting this sensor network into a smart sensor network for M2M communications, High data rates, lower latency and other breakthrough technologies deployed in $5 \mathrm{G}$ support WSNs in providing better service. Smart devices will be used in new applications due to the presence of 5G [67]-[69]. But foster the use of WSNs in $5 \mathrm{G}$, one needs to make sure that such fundamental properties of WSN devices, as low data rate, massive number of devices, minimum data rates in virtually all circumstances, etc., are compatible [70]-[72].

One way to make this convergence possible is to improve the performance of ZigBee networks which connect all sensor nodes in the $5 \mathrm{G}$ environment, as shown in Fig. 8. Thanks to $5 \mathrm{G}$, a technology providing M2M communications, terminals which are located within the range of the ZigBee network are able to connect to the ZigBee network [73]. Compared to ZigBee sensor nodes, 5G terminals have more energy, offer storage space, bandwidth and processing power, improving data transmission per- 


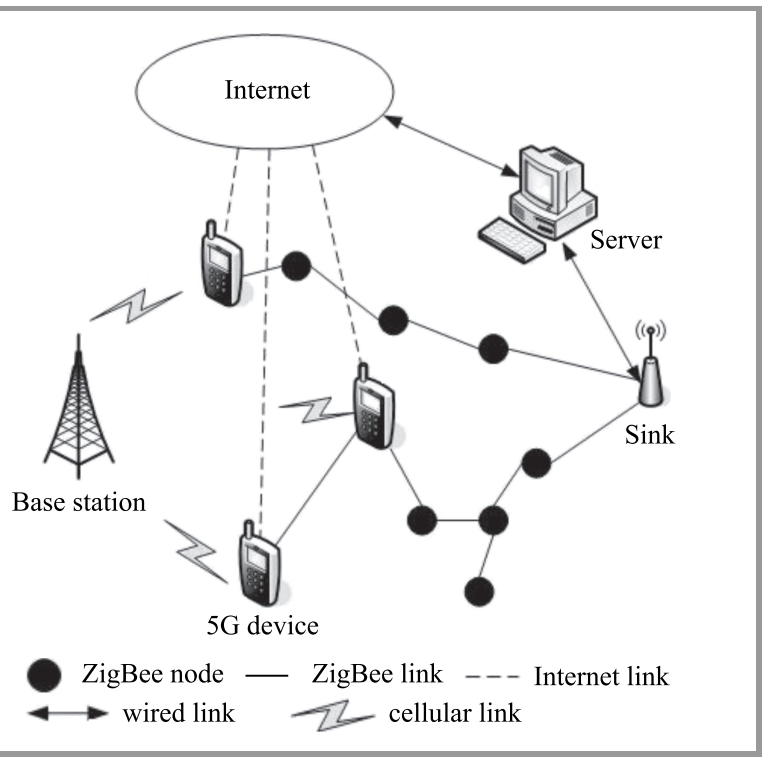

Fig. 8. WSN-5G convergence architecture.

formance of the WSN (ZigBee network). 5G terminals access the IP network as well, making them capable of communicating sink management-related information directly, without consuming ZigBee bandwidth resources. This means that convergence of WSN and $5 \mathrm{G}$ allows to convey the packets collected by WSN via $5 \mathrm{G}$ links (the Internet).

\section{Future Research Issues}

The purpose of this review is to discuss issues related to emerging WSN-MCN convergence networks and to provide the reader with an outline of further research opportunities. The limitations of WSNs, such as lower mobility robustness, weak terminals, smaller coverage, low power, less processing capability and less storage capacity, enable the researchers to propose new and advanced communication protocols, as well as energy-efficient schemes ensuring long network lifetimes. These limitations may be overcome by the use of WSN-MCN convergence networks. In addition, the emerging smart city applications will add a new dimension to the work performed at present. The review provides also important research directions for researchers wishing to contribute to this particular field of study. Some important research issues stemming from work on WSN-MCN convergence include the following:

- traffic routing schemes in ZigBee networks need to be addressed more precisely, in order to share such traffic with $5 \mathrm{G}$ networks,

- protocol convergence between heterogeneous networks needs to provide a specific trade-off between complexity, performance and power consumption,

- the QoS issues related convergence networks require that such characteristics as probability of data loss, probability of data blocking, data latency, throughput and transmission delay be analyzed in order to maintain a good balance fostering better network performance,

- convergence networks are going to promote the development of new innovative technologies to support various smart applications, such as monitoring of military activities, home monitoring, environment monitoring and smart automatic parking - to make our everyday lives easier,

- in addition to smart city applications, convergence networks may also be useful in rural areas, turning them into smart villages.

\section{Conclusions}

The limitations of WSNs, including mobility, robustness, weak terminals and small coverage, make WSNs incapable of supporting different types of smart applications. Therefore, WSNs need to converge with MCNs in order to enable M2M communications, as numerous applications depend on this type of data exchange. Many additional applications are yet to be discovered for smart cities and smart living. Therefore, convergence has an important role to play at present and in the future. In a convergence network, MAC layer resources are to be dynamically shared by both WSN and MCN nodes in order to facilitate real time and nonreal time data exchanges. The convergence network may be treated as one of the right options to establish a communication infrastructure for smart cities. Different aspects related to smart cities, such as parking, health, home, waste and traffic management demand advanced sensor technologies in order to satisfy requirements of convergence-based applications. From the studies of various literature and research articles, we conclude that convergence networks play an important role in various smart applications, enabling efficient control and management of complete solutions. Moreover, the concept of a WSN-MCN convergence network offers researchers numerous opportunities for further studies in this area.

\section{References}

[1] I. F. Akyildiz, W. Su, Y. Sankarasubramaniam, and E. Cayirci, "Wireless sensor networks: a survey", Comp. Netw., vol. 38, no. 4, pp. 393-422, 2002 (doi: 10.1016/S1389-1286(01)00302-4).

[2] J. Yick, B. Mukherjee, and D. Ghosal, "Wireless sensor network survey”, Comp. Netw., vol. 52, no. 12, pp. 2292-2330, 2008 (doi: 10.1016/j.comnet.2008.04.002).

[3] C. Buratti, A. Conti, D. Dardari, and R. Verdone, "An overview on wireless sensor networks technology and evolution", Sensors, vol. 9, no. 9, pp. 6869-6896, 2009 (doi: 10.3390/s90906869).

[4] F. Shahzad and T. R. Sheltami, "An efficient MAC scheme in wireless sensor network with energy harvesting (EHWSN) for cloud based applications", in Proc. IEEE 40th Local Comp. Netw. Conf. Worksh. LCN Workshops 2015, Clearwater Beach, FL, USA, 2015 (doi: 10.1109/LCNW.2015.7365928). 
[5] C. Tunca, S. Isik, M. Y. Donmez, and C. Ersoy, "Ring routing: An energy-efficient routing protocol for wireless sensor networks with a mobile sink", IEEE Trans. on Mob. Comput., vol. 14, no. 9, pp. 1947-1960, 2014 (doi: 10.1109/TMC.2014.2366776).

[6] A. M. Badescu and L. Cotofana, "A wireless sensor network to monitor and protect tigers in the wild", Ecolog. Indicat., vol. 57, pp. 447-451, 2015 (doi: 10.1016/j.ecolind.2015.05.022).

[7] D. Fang, J. Hu, X. Wei, H. Shao, and Y. Luo, "A smart phone healthcare monitoring system for oxygen saturation and heart rate", in Proc. Int. Conf. on Cyber-Enab. Distrib. Comput. and Knowl. Discov., Shanghai, China, 2014, pp. 245-247 (doi: 10.1109/CyberC.2014.51).

[8] M. J. Moron et al., "J2ME and smart phones as platform for a Bluetooth body area network for patient-telemonitoring", in Proc. 29th Ann. Int. Conf. of the IEEE Eng. in Medic. and Biol. Soc., Lyon, France, 2007, pp. 2791-2794 (doi: 10.1109/IEMBS.2007.4352908).

[9] P. K. Verma et al., "Machine-to-Machine (M2M) communications: A survey", J. of Netw. and Comp. Appl., vol. 66, pp. 83-105, 2016 (doi: 10.1016/j.jnca.2016.02.016)

[10] A. P. Abidoye and I. C. Obagbuwa, "Models for integrating wireless sensor networks into the Internet of Things", IET Wirel. Sensor Syst., vol. 7, no. 3, pp. 65-72, 2017 (doi: 10.1049/iet-wss.2016.0049)

[11] J. Zhang, L. Shan, H. Hu, and Y. Yang, "Mobile cellular networks and wireless sensor networks: toward convergence", IEEE Commun. Mag., vol. 50, no. 3, pp.164-169, 2012 (doi: 10.1109/MCOM.2012.6163597).

[12] F. Hu and S. Kumar, "The integration of ad hoc sensor and cellular networks for multi-class data transmission", Ad Hoc Netw., vol. 4, no. 2, pp. 254-282, 2006 (doi: 10.1016/j.adhoc.2004.08.014).

[13] A. Attwood, M. Merabti, and O. Abuelmaatti, "IoMANETs: Mobility architecture for wireless M2M networks", in Proc. IEEE GLOBECOM Workshops GC Wkshps 2011, Houston, TX, USA, 2011, pp. 399-404 (doi: 10.1109/GLOCOMW.2011.6162479).

[14] L. Shan, Z. Li, and H. Hu, "Converged mobile cellular networks and wireless sensor networks for machine-to-machine communications", KSII Trans. on Internet \& Inform. Syst., vol. 6, pp.147-161, 2012 (doi: 10.3837/tiis.2012.01.009).

[15] G. Crosby and F. Vafa, " A novel dual mode gateway for wireless sensor network and LTE-A network convergence", Int. J. of Engin. Res. and Innov., vol. 5, no. 2, pp. 19-27, 2013 [Online]. Available: https://pdfs.semanticscholar.org/9407/ f123cf9d6e83b79e313a42038733cbf0c94a.pdf

[16] Y. Igarashi, M. Ueno, and T. Fujisaki, "Proposed node and network models for an M2M Internet", in Proc. World Telecommun. Congr., Miyazaki, Japan, 2012 [Online]. Available: https://ieeexplore.ieee.org/stamp/stamp.jsp?arnumber=6170462

[17] Z. Yuan, Y. Ouyang, L. Shan, H. Hu, and Z. Li, "A load balancing algorithm in convergent wireless sensor and cellular networks", in Proc. 8th Int. Conf. on Wirel. Commun., Netw. and Mob. Comput., Shanghai, China, 2012 (doi: 10.1109/WiCOM.2012.6478298).

[18] J. Xiao, F. Yin, H. Wang, Z. Li, F. Liu, and P. Wang, "Energyefficient data collection in WSN-MCN convergence architecture", in Proc. IEEE 14th Int. Conf. on Commun. Technol., Chengdu, China, 2012, pp. 524-530 (doi: 10.1109/ICCT.2012.6511274).

[19] V. Rajendran, K. Obraczka, and J. J. Garcia-Luna-Aceves, "Energyefficient, collision-free medium access control for wireless sensor networks", Wirel. Netw., vol. 12, no. 1, 2006, pp. 63-78 (doi: 10.1007/s11276-006-6151-z).

[20] J. Polastre, J. Hill, and D. Culler, "Versatile low power media access for wireless sensor networks", in Proc. 2nd Int. Conf. on Embed. Netw. Sensor Syst. SenSys 2004, Baltimore, MD, USA, 2004, pp. 95-107 (doi: 10.1145/1031495.1031508).

[21] H. Dubois-Ferrire, D. Estrin, and M. Vetterli, "Packet combining in sensor networks", in Proc. 3rd Int. Conf. on Embed. Netw. Sensor Syst., San Diego, CA, USA, 2005, pp. 102-115 (doi: 10.1145/1098918.1098930).

[22] S. Mishra and A. Nasipuri, "An adaptive low power reservation based MAC protocol for wireless sensor networks", in Proc. IEEE Int. Conf. on Perform., Comput., and Commun., Phoenix, AZ, USA, 2004, pp. 731-736 (doi: 10.1109/PCCC.2004.1395167).
[23] C. Guo, L. C. Zhong, and J. M. Rabaey, "Low power distributed MAC for ad hoc sensor radio networks", in Proc. IEEE Global Telecommun. Conf. GLOBECOM'01, San Antonio, TX, USA, 2001, pp. 2944-2948 (doi: 10.1109/GLOCOM.2001.965967).

[24] M. C. Vuran and I. F. Akyildiz,"Spatial correlation-based collaborative medium access control in wireless sensor networks", IEEE/ACM Trans. on Netw., vol. 14, no. 2, pp. 316-329, 2006 (doi: 10.1109/TNET.2006.872544).

[25] K. Seada, M. Zuniga, A. Helmy, and B. Krishnamachari, "Energyefficient forwarding strategies for geographic routing in lossy wireless sensor networks", in Proc. 2nd Int. Conf. on Embed. Netw. Sensor Syst. SenSys 2004, Baltimore, MD, USA, 2004, pp. 108-121 (doi: 10.1145/1031495.1031509).

[26] R. Zhang, H. Zhao, and M. A. Labrador, "The anchor location service (ALS) protocol for large-scale wireless sensor networks", in Proc. 1st Int. Conf. on Integr. Internet Ad Hoc and Sensor Netw. InterSense'06, Nice, France, 2006 (doi: 10.1145/1142680.1142704).

[27] J. Yin and S. Madria, "SecRout: a secure routing protocol for sensor networks", in Proc. 20th Int. Conf. on Adv. Inform. Netw. and Appl. AINA'06, Vienna, Austria, 2006 (doi: 10.1109/AINA.2006.297).

[28] X. Du, Y. Xiao, H. H. Chen, and Q. Wu, "Secure cell relay routing protocol for sensor networks", Wirel. Commun. and Mob. Comput., vol. 6, no. 3, pp. 375-391, 2006 (doi: 10.1002/wcm.402).

[29] A. Manjeshwar and D. P. Agrawal, "APTEEN: A hybrid protocol for efficient routing and comprehensive information retrieval in wireless sensor networks", in Proc. 16th Int. Parall. and Distrib. Process. Symp. IPDPS 2002, Fort Lauderdale, FL, USA, 2002 (doi: 10.1109/IPDPS.2002.1016600).

[30] K. Akkaya and M. Younis, "An energy-aware QoS routing protocol for wireless sensor networks", in Proc. 23rd Int. Conf. on Distrib. Comput. Syst. Worksh., Providence, RI, USA, 2003, pp. 710-715 (doi: 10.1109/ICDCSW.2003.1203636).

[31] E. Felemban, C. G. Lee, and E. Ekici, "MMSPEED: multipath MultiSPEED protocol for QoS guarantee of reliability and timeliness in wireless sensor networks", IEEE Trans. on Mob. Сотри., vol. 5, no. 6, pp. 738-754, 2006 (doi: 10.1109/TMC.2006.79)

[32] A. R. Swain, R. C. Hansdah, and V. K. Chouhan, " An energy aware routing protocol with sleep scheduling for wireless sensor networks", in 2Proc. 4th IEEE Int. Conf. on Adv. Inform. Netw. and Appl., Perth, WA, Australia, 2010, pp. 933-940 (doi: 10.1109/AINA.2010.11).

[33] Y. G. Iyer, S. Gandham, and S. Venkatesan, "STCP: a generic transport layer protocol for wireless sensor networks", in Proc. 14th Int. Conf. on Comp. Commun. and Netw. ICCCN 2005, San Diego, CA, USA, 2005, pp. 449-454 (doi: 10.1109/ICCCN.2005.1523908).

[34] Y. Zhou, M. R. Lyu, J. Liu, and H. Wang, "PORT: a price-oriented reliable transport protocol for wireless sensor networks", in Proc. IEEE Int. Symp. on Softw. Reliabil. Engin. ISSRE'05, Chicago, IL, USA, 2005 (doi: 10.1109/ISSRE.2005.32).

[35] V. C. Gungor and O. B. Akan, " DST: delay sensitive transport in wireless sensor networks", in Proc. Int. Symp. on Comp. Netw., Istanbul, Turkey, 2006, pp. 116-122 (doi: 10.1109/ISCN.2006.1662519).

[36] C. Y. Wan, A. T. Campbell, and L. Krishnamurthy, "PSFQ: a reliable transport protocol for wireless sensor networks", in Proc. 1st ACM Int. Worksh. on Wirel. Sensor Netw. and Appl., Atlanta, GA, USA, 2002 (doi: 10.1145/570738.570740).

[37] Y. Sankarasubramaniam, B. Akan, and I. F. Akyildiz, "ESRT: eventto-sink reliable transport in wireless sensor networks", in Proc. 4th ACM Int. Symp. on Mob. Ad Hoc Netw. \& Comput. MobiHoc 2003, Annapolis, MD, USA, 2003, pp. 177-188 (doi: 10.1145/778415.778437).

[38] C. Y. Wan, S. B. Eisenman, and A. T. Campbell, "CODA: congestion detection and avoidance in sensor networks", in Proc. 1st Int. Conf. on Embed. Netw. Sensor Syst., Los Angeles, CA, USA, 2003, pp. 266-279 (doi: 10.1145/958522.958523).

[39] S. J. Park, R. Vedantham, R. Sivakumar, and I. F. Akyildiz, "A scalable approach for reliable downstream data delivery in wireless sensor networks", in Proc. 5th ACM Int. Symp. on Mob. Ad Hoc Netw. and Comput. MobiHoc 2004, Tokyo, Japan, 2004, pp. 78-89 (doi: 10.1145/989459.989470). 
[40] P. Baronti et al., "Wireless sensor networks: A survey on the state of the art and the 802.15. 4 and ZigBee standards", Computer Commun., vol. 30, no. 7, pp. 1655-1695, 2007 (doi: 10.1016/j.comcom.2006.12.020).

[41] J. S. Lee and Y. C. Huang, "ITRI ZBnode: A ZigBee/IEEE 802.15. 4 platform for wireless sensor networks", in Proc. IEEE Int. Conf. on Syst., Man and Cybernet., Taipei, Taiwan, 2006, pp. 1462-1467 (doi: 10.1109/ICSMC.2006.384923).

[42] N. Baker, "ZigBee and Bluetooth: Strengths and weaknesses for industrial applications", Comput. and Control Engin. J., vol. 16, no. 2, pp. 20-25, 2005 (doi: 10.1049/cce:20050204).

[43] J. M. Cramer, R. A. Scholtz, and M. Z. Win, "On the analysis of UWB communication channels", in Proc. IEEE Military Commun. Conf. MILCOM 1999, Atlantic City, NJ, USA, 1999, pp. 1191-1195 (doi: 10.1109/MILCOM.1999.821392).

[44] J. S. Lee, Y. W. Su, and C. C. Shen, "A comparative study of wireless protocols: Bluetooth, UWB, ZigBee, and Wi-Fi”, in Proc. 33rd Ann. Conf. of the IEEE: Industr. Electron. Soc. IECON 2007, Taipei, Taiwan, 2007, vol. 5, pp. 46-51 (doi: 10.1109/IECON.2007.4460126).

[45] J. Kooker, "Bluetooth, ZigBee, and Wibree: A comparison of WPAN technologies", 2008 [Online]. Available: https://cseweb.ucsd.edu/classes/fa08/cse237a/topicresearch/ jkooker_tr_report.pdf

[46] S. Chhajed, M. Sabir, and K. P. Singh, "Wireless Sensor Network implementation using MiWi wireless protocol stack", in Proc. IEEE Int. Adv. Comput. Conf. IACC 2014, Gurgaon, India, 2014, pp. 239-244 (doi: 10.1109/IAdCC.2014.6779327).

[47] N. H. A. Ismail, R. Hassan, and K. W. Ghazali, "A study on protocol stack in 6lowpan model", J. of Theoret. and Appl. Inform. Technol., vol. 41, no. 2, pp. 220-229, 2012 [Online]. Available: http://www.jatit.org/volumes/Vol41No2/12Vol41No2.pdf

[48] E. Toscano and L. L. Bello, "Comparative assessments of IEEE 802.15. 4/ZigBee and 6LoWPAN for low-power industrial WSNs in realistic scenarios", in Proc. 9th IEEE Int. Worksh. on Factory Commun. Syst., Lemgo, Germany, 2012, pp. 115-124 (doi: 10.1109/WFCS.2012.6242553).

[49] G. Mulligan, "The 6LoWPAN architecture", in Proc. 4th Worksh. on Embed. Netw. Sens. EmNets 2007, Cork, Ireland, 2007, pp. 78-82 (doi: 10.1145/1278972.1278992).

[50] L. M. Oliveira, J. J. Rodrigues, A. G. Elias, and G. Han, "Wireless sensor networks in IPv4/IPv6 transition scenarios", Wireless Pers. Commun., vol. 78, no. 4, pp. 1849-1862, 2014 (doi: 10.1007/s11277-014-2048-9).

[51] P. A. Neves and J. J. Rodrigues, "Internet protocol over wireless sensor networks, from myth to reality", J. of Commun., vol. 5, no. 3, pp.189-196, 2010 (doi: 10.4304/jcm.5.3.189-196).

[52] N. Kushalnagar, G. Montenegro, and C. Schumacher, "IPv6 over low-power wireless personal area networks (6LoWPANs): overview, assumptions, problem statement, and goals”, RFC 4919, IETF, 2007 (doi: 10.17487/RFC4919) [Online]. Available: https://tools.ietf.org/html/rfc4919

[53] J. Feng, L. Zheng, J. Fu, and Z. Liu, "An optimum gateway discovery and selection mechanism in WSN and mobile cellular network integration", in Proc. 8th Int. Conf. on Commun. and Netw. in China CHINACOM 2013, Guilin, China, 2013, pp. 483-487 (doi: 10.1109/ChinaCom.2013.6694644).

[54] J. Xia, R. Yun, K. Yu, F. Yin, H. Wang, and Z. Bu, "Coordinated multimode (cellular-WSN) user equipment accessing wireless sensor network mechanism", in Proc. 4th Int. Conf. on Intell. Netw. and Collab. Syst., Bucharest, Romania, 2012, pp. 550-555 (doi: 10.1109/iNCoS.2012.19).

[55] S. A. Munir, B. Ren, W. Jiao, B. Wang, D. Xie, and J. Ma, "Mobile wireless sensor network: Architecture and enabling technologies for ubiquitous computing", in Proc. 21st Int. Conf. on Adv. Inform. Netw. and Appl. Worksh. AINAW'07, Niagara Falls, Ontario, Canada, 2007, pp. 113-120 (doi: 10.1109/AINAW.2007.257).

[56] C. Y. Wong, R. S. Cheng, K. B. Lataief, and R. D. Murch, "Multiuser OFDM with adaptive subcarrier, bit, and power allocation", IEEE J. on Selec. Areas in Commun., vol. 17, no. 10, pp. 1747-1758, 1999 (doi: 10.1109/49.793310).
[57] T. Wang, C. Yang, G. Wu, S. Li, and G. Y. Li, "OFDM and its wireless applications: A survey", IEEE Trans. on Veh. Technol., vol. 58, no. 4, pp. 1673-1694, 2008 (doi: 10.1109/TVT.2008.2004555).

[58] R. Rajbanshi, A. M. Wyglinski, and G. J. Minden, "An efficient implementation of NC-OFDM transceivers for cognitive radios", in Proc. 1st Int. Conf. on Cognit. Radio Orien. Wirel. Netw. and Commun., Mykonos Island, Greece, 2006 (doi: 10.1109/CROWNCOM.2006.363452).

[59] R. Nossenson, "Long-term evolution network architecture", in Proc. IEEE Int. Conf. on Microw., Commun., Antenn. and Electron. Syst., Tel Aviv, Israel, 2009 (doi: 10.1109/COMCAS.2009.5385947).

[60] S. Y. Lien, K. C. Chen, and Y. Lin, "Toward ubiquitous massive accesses in 3GPP machine-to-machine communications", IEEE Commun. Mag., vol. 49, no. 4, pp. 66-74, 2011

(doi: 10.1109/MCOM.2011.5741148).

[61] B. Clerckx , A. Lozano, S. Sesia, C. Van Rensburg, and C. B. Papadias, "3GPP lte and LTE-advanced", J. on Wirel. Commun. and Netw., vol. 2009, Article No. 472124, 2009

(doi: 10.1155/2009/472124).

[62] S. B. H. Said et al., "New control plane in 3GPP LTE/EPC architecture for on-demand connectivity service", in Proc. IEEE 2nd Int. Con. on Cloud Netw. CloudNet 2013, San Francisco, CA, USA, 2013, pp. 205-209 (doi: 10.1109/CloudNet.2013.6710579).

[63] V. Sevindik, J. Wang, O. Bayat, and J. Weitzen, "Performance evaluation of a real long term evolution (LTE) network", in Proc. 37th Ann. IEEE Conf. on Local Comp. Netw. - Workshops, Clearwater, FL, USA, 2012, pp. 679-685 (doi: 10.1109/LCNW.2012.6424050).

[64] S. Chen, J. Hu, Y. Shi, and L. Zhao, "LTE-V: A TD-LTE-based V2X solution for future vehicular network", IEEE Internet of Things J., vol. 3, no. 6, pp. 997-1005, 2016 (doi: 10.1109/JIOT.2016.2611605).

[65] G. V. Crosby and F. Vafa, "Wireless sensor networks and LTEA network convergence", in Proc. 38th Ann. IEEE Con. on Local Comp. Netw., Sydney, NSW, Australia, 2013, pp. 731-734 (doi: 10.1109/LCN.2013.6761322).

[66] L. Shan, W. Fang, F. Li, and Y. Sun, " Performance analysis of mobile smart UE-gateway assisted transmission algorithm for wireless sensor networks", in High Performance Computing and Applications Third International Conference, HPCA 2015, Shanghai, China, July 26-30, 2015, Revised Selected Papers, J. Xie, Z. Chen, C. C. Douglas, W. Zhang, and Y. Chen, Eds. LNCS, vol. 9576, pp. 134-142. Springer, 2015 (doi: 10.1007/978-3-319-32557-6_14).

[67] A. Zakrzewska, S. Ruepp, and M. S. Berger, "Towards converged 5G mobile networks-challenges and current trends", in Proc. of the 2014 ITU Kaleidoscope Academic Conf.: Living in a Converged WorldImpossible without Standards?, St. Petersburg, Russia, 2014 (doi: 10.1109/Kaleidoscope.2014.6858478).

[68] H. Yu, H. Lee, and H. Jeon, "What is 5G? Emerging 5G mobile services and network requirements", Sustainability, vol. 9, no. 10, 2017 (doi: 10.3390/su9101848).

[69] S. Li, L. Xu, and S. Zhao, "5G Internet of Things: A survey", J. of Indust. Inform. Integr., vol. 10, pp. 1-9, 2018 (doi: 10.1016/j.jii.2018.01.005).

[70] C. Wang, J. Bian, J. Sun, W. Zhang, and M. Zhang, "A survey of 5G channel measurements and models", IEEE Commun. Surv. \& Tutor., vol. 20, no. 4, pp. 3142-3168, 2018 (doi: 10.1109/COMST.2018.2862141).

[71] F. Al-Turjman, "5G-enabled devices and smart-spaces in social-IoT: an overview", Fut. Gener. Comp. Syst., vol. 92, pp. 732-744, 2019 (doi: 10.1016/j.future.2017.11.035).

[72] V. Kumar et al., "5G cellular: Concept, research work and enabling technologies", in Advances in Data and Information Sciences. Proceedings of ICDIS 2017, Volume 2, M. L. Kolhe, M. C. Trivedi, S. Tiwari, and V. K. Singh, Eds. LNNS, vol. 39, pp. 327-338. Springer, 2019 (doi: 10.1007/978-981-13-0277-0_27).

[73] J. Mu and L. Han, "Performance analysis of the ZigBee networks in $5 \mathrm{G}$ environment and the nearest access routing for improvement", Ad Hoc Netw., vol. 56, 2017 (doi: 10.1016/j.adhoc.2016.10.006). 


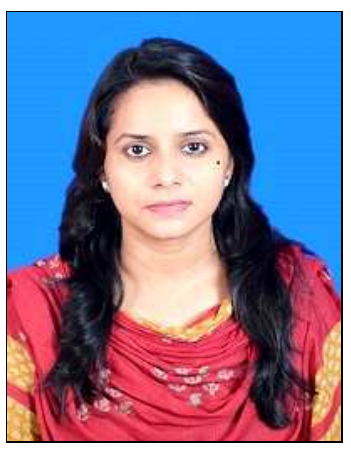

Anita Swain received her B.Tech. and M.Tech. degree from Biju Patnaik University of Technology, Bhubaneswar, India. She is currently pursuing her Ph.D. in Electronics and Communication Engineering at KIIT Deemed to be University, India. Her research interests include wireless sensor network, wireless communication and mobile communication. She has published research paper in international journals and conference proceedings.

E-mail: anita.swain0703@gmail.com

School of Electronics Engineering

KIIT Deemed to be University

Bhubaneswar, India

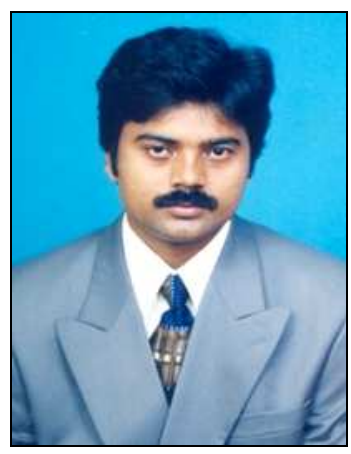

Arun Kumar Ray is currently Professor at the School of Electronics Engineering, KIIT Deemed to be University. He received his B.Tech. from CET, Bhubanceswar, India and M.Tech. from Jadavpur University Kolkata, India. He has completed his Ph.D. from IIT Kharagpur, India. His research interests include image processing and computer networks.

E-mail: arunkumarray2000@gmail.com

School of Electronics Engineering

KIIT Deemed to be University

Bhubaneswar, India 751024 